\title{
Dynamic Analysis on the Volatility of China Stock Market Based on CSI 300: A Financial Security Perspective
}

\author{
Xiongbing Chen ${ }^{1, *}$ and Ning Zhang ${ }^{2}$ \\ ${ }^{1}$ Economics and Management school, Wuhan University, 430072, Wuhan, China \\ ${ }^{2}$ School of Economics, Renmin university of China, Beijing, China \\ * chenxiongbing@hotmail.com
}

\begin{abstract}
With the acceleration of information dissemination, the rapid flow of capital will make stock price changes. At the same time, the change of stock price also affects the market; its volatility is a measure of the quality and efficiency of the stock market. Research on the volatility of financial markets can effectively prevent the generation of financial risks. In this paper, the authors make a dynamic analysis on the volatility of China stock market based on CSI 300 index. Through the empirical analysis, the results show that the model can reflect the volatility of the stock market returns in our country, and the accuracy is high. At the same time, the test results show that the volatility of the stock price has a leverage effect, and the volatility caused by bad news will be large than the volatility caused by good news.
\end{abstract}

Keywords: Stock market, Volatility, Financial security, GARCH model

\section{Introduction}

The stock market is full of uncertainty, the market situation is in the process of changing. In today's society, rapid dissemination of information, the rapid flow of capital will make stock price changes and changes in stock prices will also affect the market, both influence each other mutual conduction and its volatility is to measure the quality and efficiency of the stock market, the main reference. Fluctuations in the range of normal range is conducive to the active market, so that the market can continue to carry out, but too frequent fluctuations in the market will increase the risk of investors to judge, is not conducive to the good operation of the market[1]. China's stock market belongs to the emerging market range, has been China's stock market volatility and the fluctuation characteristic of high risk is also very obvious, often appear the phenomenon of big ups and downs[2-3]. All of these are the most representative characteristics of the stock market of our country. Especially after the split share structure reform, the non tradable shares are gradually transformed into tradable shares, which has further increased the volatility of China's stock market. This kind of excessive fluctuation has great influence on China's financial system and the national economy. Therefore, this paper will focus on China's Shanghai and Shenzhen stock index volatility, asymmetric volatility to understand, grasp the market of our country exist leverage effect and so on, to our country government management as well as the majority of investors has a strong practical significance.

Volatility is the basic nature of the stock market, the volatility of the stock price is the necessary condition for the allocation of resources in the capital market[4]. For investors, it can be expected to measure the volatility of the risk of exposure to the size, at the same time, the volatility of the grasp will help to define the stock price in a range of possible. Therefore, volatility is also the basis for investors to gain income. As an investor, it is concerned with the analysis of the securities market price behavior as accurately as possible, in order to make a reasonable forecast of the future market yield[5-6]. The 
Shanghai and Shenzhen 300 index reflects the stock price changes in China's securities market profile and the trend, the study of the volatility of the index return, to provide a correct reference for its investment decisions[7]. For a long time, volatility is an important field in the research of financial risk, which is usually measured by the standard deviation or variance of the asset return rate[8]. But a lot of research results show that the volatility is not simple to show the characteristics of the normal distribution, and changes with time. Econometrics is evolving, and a variety of models that are derived from this model are constantly emerging, trying to explain this volatility. In this paper, the use of GARCH model on the Shanghai and Shenzhen 300 index daily yield to do research, enrich the theory of volatility in our country.

\section{Theoretical Model}

\subsection{The ARCH Model}

ARCH model, also known as Conditional Heteroscedasticity Model Autoregressive, the main core is the time $t$ of the variance is by the time ( $t-1)$ of the size of the square error and influence,

$$
Y_{t}=\beta_{0}+\beta_{1} X_{1 t}+\Lambda \Lambda+\beta_{k} X_{k t}+\varepsilon_{t}
$$

Under all information conditions, (t-1) time, the interference is more than one, and the distribution of the interference term is:

$$
\varepsilon_{t} \sim N\left(0,\left(\alpha_{0}+\alpha_{1} \varepsilon_{t-1}^{2}\right)\right)
$$

$\mathrm{ARCH}(\mathrm{P})$ process is the extension of the interference term:

$$
\begin{aligned}
& \operatorname{Var}\left(\varepsilon_{t}\right)=\sigma_{t}^{2}=\alpha_{0}+\alpha_{1} \varepsilon_{t-1}^{2}+\alpha_{2} \varepsilon_{t-2}^{2} \\
& \quad+\Lambda \Lambda+\alpha_{p} \varepsilon_{t-p}^{2}
\end{aligned}
$$

If there is no self correlation exists in the error variance, there will be $\mathrm{H} 0=\mathrm{a} 1=\mathrm{a} 2$. result is the same variance in the variance of the error variance. Engel has used the following regression to test the hypothesis of the above:

$$
\widehat{\varepsilon}_{t}^{2}=\widehat{\alpha}_{0}+\widehat{\alpha}_{1} \varepsilon_{t-1}^{2}+\hat{\alpha}_{2} \varepsilon_{t-2}^{2}+\Lambda \Lambda+\widehat{\alpha}_{p} \varepsilon_{t-p}^{2}
$$

In the original regression model (1), we estimate the OLS residuals obtained.

(1) GARCH $(1,1)$ model

Empirical analysis shows that the GARCH model has a better grasp of the financial market data analysis, the characteristics of financial data are fully reflected, and is respected and widely used. The most simple GARCH model is the standardization of GARCH $(1,1)$ :

$$
\begin{gathered}
y_{t}=x_{t} \gamma+\varepsilon_{t} \\
\sigma_{t}^{2}=\omega+\alpha \varepsilon_{t-1}^{2}+\beta \sigma_{t-1}^{2}
\end{gathered}
$$

$\mathrm{X}$ represents an exogenous or pre - decision variable introduced in the mean equation. If we introduce conditional variance into the mean equation, we can get the $\mathrm{M}-\mathrm{ARCH}$ model

$$
y_{t}=x_{t}^{\prime} \gamma+\beta \sigma_{t}^{2}+\varepsilon_{t}
$$

The conditional variance is replaced by the conditional standard deviation, which is another form of M - ARCH model. M - ARCH model is usually used in the financial field of the expected return on assets and the expected risk relationship. The estimated risk is a trade-off between risk and return.

(2) GARCH (P, q) model

Based on the arch model $\mathrm{Q}$ may be relatively large, bollerslev the $\operatorname{arch}(\mathrm{P}, \mathrm{q})$ model is extended, an effective solution to the number of parameters is usually higher: using $\operatorname{GARCH}(\mathrm{P}, \mathrm{q})$ model, and the fluctuation of rate by its hysteresis representation and is the 
same as that of mean variance and arch model, difference equation in a slightly different. High order GARCH model can be estimated by using more than 1 of $\mathrm{P}$ or $\mathrm{Q}$, denoted as $\mathrm{GARCH}(\mathrm{P}, \mathrm{Q})$. Its variance is expressed as:

$$
\sigma_{t}^{2}=\omega+\sum_{i=1}^{a} a_{i} \varepsilon_{t-1}^{2}+\sum_{j=1}^{p} \beta_{j} \sigma_{t-j}^{2}
$$

\subsection{GARCH Model}

The upward movement of assets is often accompanied by a stronger downward movement, which is a common phenomenon in the financial markets. In order to explain this kind of phenomenon, Engle and ng drawn respectively under the influence of the information curve in under the influence of the good news and bad news of the information curve combination of asymmetric information curve, and to determine in financial markets in the asymmetric effect is the market on the impact of the basic form, the non symmetry effect in the financial markets is the formation of the "leverage effect", the effect is also a lot of financial assets is the important characteristic of fact, fluctuations in the market fell when the rate of reaction to than rising market reaction is much stronger, and more quickly[9]. In the actual capital market, market analysts often found that there is asymmetric behavior of stock price when the stock produce fluctuations caused by the negative impact is often compared to stock fluctuations caused by the positive impact is much greater. Because the share price dropped significantly, reducing the owner's equity, increased the company's leverage, but also increased the risk of holding company stock. The TGARCH model and the EGARCH model are the two main models to describe the asymmetric shocks.

(1) TARCH model

The model can better simulate the "leverage effect" of financial market, and it has the conditional variance of the following form:

$$
\sigma_{t}^{2}=\omega+\alpha \varepsilon_{t-1}^{2}+\gamma \varepsilon_{t-1}^{2} d_{t-1}+\beta \sigma_{t-1}^{2}
$$

In this model, the effect of good news $(>0)$ and bad news $<$ on the conditional variance is quite different: the good news is the impact of a; the bad news is a shock to the is. If gamma $>0$, we say that there is leverage effect; if the gamma 0 , then the information is asymmetrical. TARCH model, which is a leverage effect by the output (gamma) in $($ RESID $<0) * A R C H(1)$ item description.

\section{(2) EGARCH model}

Linear GARCH model assumptions: is equal to the absolute value of the positive factors and negative factors caused by fluctuations in the same, that is, the conditional variance is the same, the results of the final reaction should be for absolute value equal to the positive and negative impact caused yield fluctuations are symmetric and equal. But in reality, especially in the financial market, the absolute value of equal positive and negative impact caused by the fluctuations are often different, as reflected in the stock market is often share price decline is far greater than the rate of increase, and down the process to be more intense, more volatile. It is obvious that the volatility of the stock market cannot be explained by the linear GARCH model before. Nelson (1991) proposed the EGARCH or index (Exponential) GARCH model. But the symmetric conditional variance function is not completely accurate, especially in the case of the negative correlation between the return rate of the previous period and the market fluctuation. In order to avoid this kind of situation and complete the non negative hypothesis of the parameters, the conditional variance is specified as the basis of the GARCH model:

$$
\log \left(\sigma_{t}^{2}\right)=\omega+\beta \log \left(\sigma_{t-1}^{2}\right)+\alpha\left|\frac{\varepsilon_{t-1}}{\sigma_{t-1}}\right|+\gamma \frac{\varepsilon_{t-1}}{\sigma_{t-1}}
$$

The advantages of this model is that the conditional variance of the data as a logarithmic form, so the variance is greater than 0 , then there is no need for other 
restrictions are added to the formula, because there is no any constraint in the model parameters, making the solution process is simpler, more flexible.

\section{The Empirical Analysis}

\subsection{Data Description}

The China Financial Futures Exchange in Shanghai and Shenzhen 300 index in January 2006 to 2015 on the 7th of each trading day closing price as the original data, in order to study the volatility of the stock market, in their estimates in Shanghai and Shenzhen 300 daily return rate as variables to investigate, in order to reduce the error, the day return rate of natural logarithm processing, is the Shanghai and Shenzhen 300 index daily return to adjacent two days of the closing index of the log first difference said, then yields the formula:

$$
r=\log \left(\frac{p_{t}}{p_{t-1}}\right)
$$

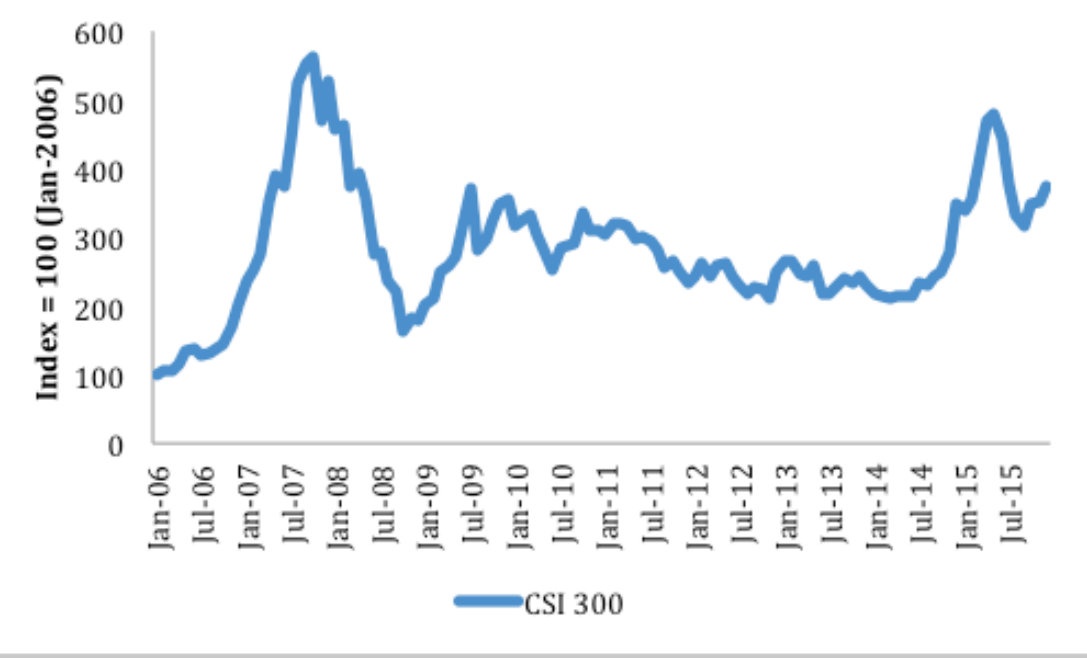

Figure 1. The Shanghai and Shenzhen 300 Index

Figure 2 for the Shanghai and Shenzhen 300 index daily rate of return of RSH000300 fluctuations, the chart can be seen that the daily yield of the volatility of the performance of the time variability, sudden and cluster characteristics. Observation of these data, we can find that the sample period in Shanghai and Shenzhen 300 index return rate average RSH000300 $0.0430 \%$, standard deviation for $2.1320 \%$, skewness is -0.404941 , left Pianfeng degree for 4.929708 far higher than 3, rate of return $\mathrm{R}$ with high peak and fat tail characteristic of the kurtosis of the normal distribution of values. The JB statistic is 242.7073, and its normality tests also confirm this feature, and the yield of $R$ is significantly different from state distribution at the minimum level. It is not possible to test the yield sequence if the sequence of the F test or all the statistical methods based on normal distribution are not tested. 


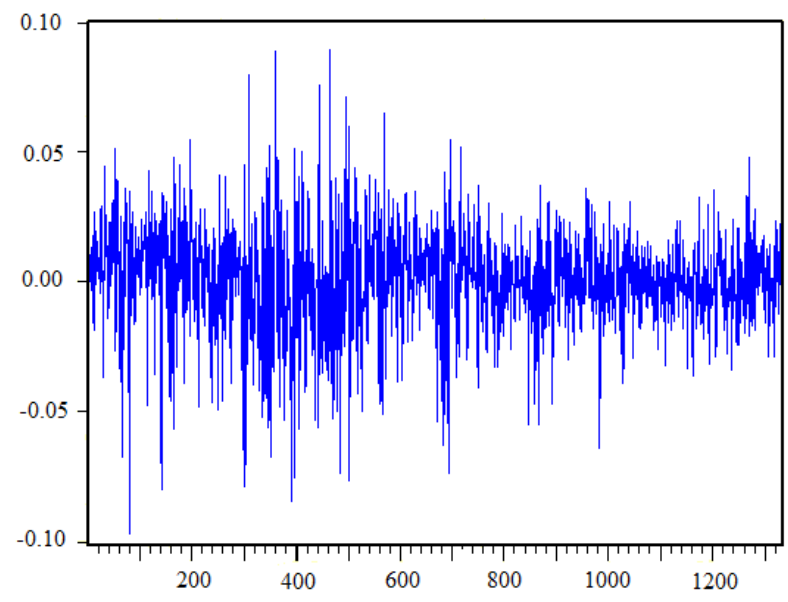

Figure 2. CSI 300 Index Fluctuations
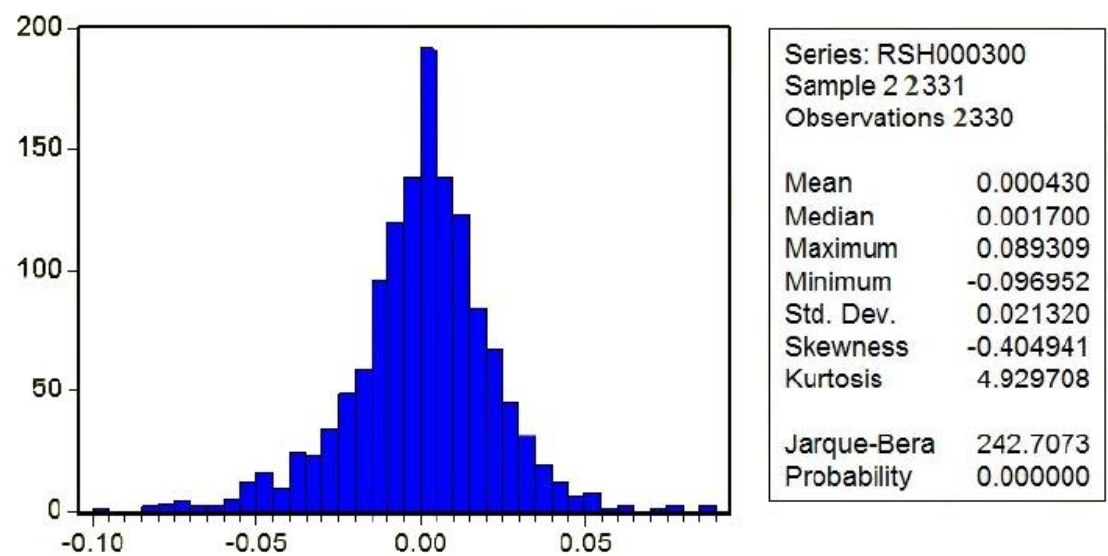

Figure 3. Descriptive Statistics of the Shanghai and Shenzhen 300 Index

\subsection{Stability Test}

The most commonly used method in the stability test is the unit root method, which is a method to determine whether the correlation coefficient is equal to 1 . After nearly 30 years of academic research, this method is finally summarized as ADF test, which can be seen from the above descriptive statistical analysis, the yield sequence around the volatility in the mean, there is no trend. Therefore the sequence of ADF unit root test, selecting lag of order 4, with intercept and trend. The test results are in Table 1.

Table 1. Unit root test

\begin{tabular}{|c|c|c|c|}
\hline \multicolumn{2}{|c|}{ Lag Length: 4 (Fixed) } & t-Statistic & Prob.* \\
\hline \multicolumn{2}{|c|}{ Augmented Dickey-Fuller test statistic } & -15.17516 & 0.0000 \\
\hline \multirow{3}{*}{ Test critical values: } & $1 \%$ level & -3.5987 & 0.0000 \\
\cline { 2 - 4 } & 5\% level & -2.0541 & 0.0000 \\
\cline { 2 - 4 } & $10 \%$ level & -2.1298 & 0.0000 \\
\hline
\end{tabular}




\subsection{ARCH Effect Test}

In this paper, we use time series model to analyze, so we should first choose the lag order of the rate of return. The mean equation of the Shanghai and Shenzhen 300 index returns takes the following form:

$$
r_{t}=c_{0}+\sum_{i=1}^{n} c_{i} r_{t-1}+\varepsilon_{t}
$$

According to the AIC statistic judgment can be seen lag phase 4 is the best, of squared residuals do linear graph, visible fluctuations of the regression equation of the residual has "swarms" phenomenon: very small fluctuations in the longer period of time, in some other longer period of time is very large, that is obvious time variability (time varying) and clustered (clustering), indicating that residual series has high level arch effect, suitable for use GARCH model to modeling, and can be observed in the stock index futures listed this year volatility significantly weakened.

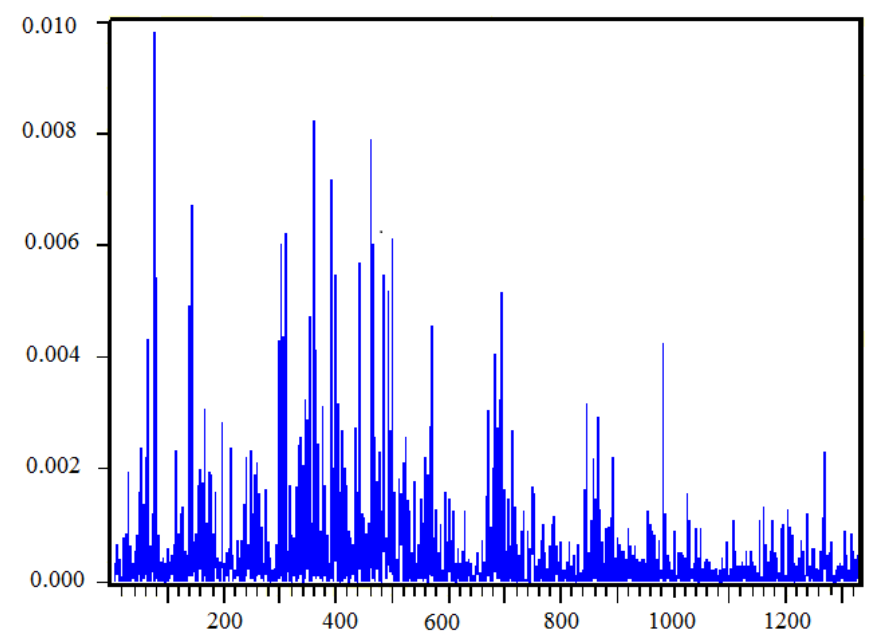

Figure 4. Residual Square Linear Graph

Table 2. ARCH Test

\begin{tabular}{|c|l|l|l|}
\hline F-statistic & 9.356201 & Probability & 0.000000 \\
\hline Obs*R-squared & 87.67942 & Probability & \\
\hline
\end{tabular}

The residual error of the linear regression is ARCH-LM test, and the F statistic of the test object is the joint significance of the squared residual error. The Obs*R2 statistic is the LM test statistic, which is the observed value of the number T multiplied by the test regression R2. Given significance level $\mathrm{a}=0.05$ and 10 degrees of freedom, the LM values for 87.67942 , with probability $\mathrm{p}$ for 0 , less than 0.05 , reject the null hypothesis, that yield sequence has obvious heteroscedasticity phenomena and residuals with strong arch effect, so this paper adopts GARCH model to fit the data of the Shanghai and Shenzhen 300 index yield rate is reasonable.

\subsection{GARCH Model}

The estimated CSI 300 index return volatility of the model results are shown in Table 3 shows, visible in the Shanghai and Shenzhen 300 index return rate in the conditional variance equation, whether it is arch or GARCH phenomena were highly significantly. The significant that rate of return volatility has a set of clusters of features. The ARCH term of the CSI 300 index return and the sum of the GARCH items is 0.974036 and is less than 1 , which meets the constraint conditions of the parameters. But because the two 
coefficients and very close to 1 , that impact on the conditional variance of the impact is not short is transient but a persistent process, through the feature inference impact on future prediction has an important role, so the GARCH $(1,1)$ is a stationary process. However, conditional variance performance is fluctuations in the past to a limited extent, its impact on the future in the gradual decay to zero, known as mean reversion.

Table 3. GARCH $(1,1)$ Estimate Model

\begin{tabular}{|c|c|c|c|c|}
\hline & Coefficient & Std. Error & z-Statistic & Prob. \\
\hline C & 0.001124 & 0.000598 & 1.754822 & 0.0697 \\
\hline index yield & 0.030354 & 0.032034 & 0.936704 & 0.2978 \\
\hline & \multicolumn{5}{|c|}{ Variance Equation } \\
\hline C & $6.54 \mathrm{E}-03$ & $2.35 \mathrm{E}-03$ & 3.278215 & 0.0011 \\
\hline ARCH(1) & 0.056411 & 0.024250 & 5.657411 & 0.0000 \\
\hline GARCH(1) & 0.917625 & 0.035285 & 72.56724 & 0.0000 \\
\hline \multicolumn{5}{|c|}{$r_{1}=0.001124+0.30354 \gamma$} \\
$\sigma_{t}^{2}=6.54 \times 10^{-3}+0.05641 \varepsilon_{t-1}^{2}+0.91762 \sigma_{t-1}^{2}$
\end{tabular}

According to GARCH-M (1,1) model estimation results, as shown in Table 4. The Shanghai and Shenzhen 300 index yield rate coefficients in the mean equation conditional variance GARCH estimation is 3.579418 and significant. This reflects the revenue and risk is related to that income is high risk more, income about risk is small with to change. It is proved that the income has a positive risk premium. And from the empirical results can be drawn from the Shanghai and Shenzhen 300 index of the rate of return of ARCH items and the sum of GARCH is 0.986334 and less than 1, to meet the stable conditions.

Table 4. GARCH-M $(1,1)$ Estimate Model

\begin{tabular}{|c|c|c|c|c|}
\hline & Coefficient & Std. Error & z-Statistic & Prob. \\
\hline GARCH & 3.579418 & 2.462104 & 2.197836 & 0.276 \\
\hline C & -0.000514 & 0.003623 & -0.145603 & 0.549 \\
\hline index yield & 0.0745603 & 0.054868 & 1.579819 & 0.681 \\
\hline & \multicolumn{4}{|c|}{ Variance Equation } \\
\hline C & $6.28 \mathrm{E}-03$ & $2.36 \mathrm{E}-03$ & 3.984505 & 0.0040 \\
\hline ARCH(1) & 0.049361 & 0.017850 & 5.794811 & 0.0000 \\
\hline GARCH(1) & 0.872645 & 0.015425 & 81.48794 & 0.0000 \\
\hline
\end{tabular}

$$
\begin{aligned}
& r_{1}=-0.00051+0.07456 \gamma+3.57941 \sigma^{2} \\
& \sigma_{t}^{2}=6.28 \times 10^{-3}+0.04936 \varepsilon_{t-1}^{2}+0.87264 \sigma_{t-1}^{2}
\end{aligned}
$$

Study on the asymmetric volatility of the Shanghai and Shenzhen 300 index returns, as shown in Table 5. In the tarch, to the term leverage effect by the RESID $<0 * A R C H$ (1) to describe, and the coefficient estimates values for 0.058912 , is significantly positive, so there are asymmetric effect, at the same time that the fluctuations of stock prices in China's Shanghai and Shenzhen 300 index is "leverage effect": and fluctuation caused by the bad news to fluctuations caused by the good news with the same degree than to much more: when the "good news", the impact of a $a=0.077813$; and the emergence of the "bad news", is will bring the impact of $\mathrm{a}+\mathrm{r}=0.077813+0.058912=0.136725$ 
Table 5. TARCH Estimate Model Result

\begin{tabular}{|c|c|c|c|c|}
\hline & Coefficient & Std. Error & z-Statistic & Prob. \\
\hline C & 0.000872 & 0.000740 & 1.89028 & 0.1025 \\
\hline index yield & 0.041267 & 0.005781 & 1.57101 & 0.5466 \\
\hline C & $1.58 \mathrm{E}-04$ & $4.02 \mathrm{E}-05$ & 3.467897 & 0.0005 \\
\hline 0.042563 & 0.077813 & 0.020131 & 2.541047 & 0.0036 \\
\hline (RESID<0)*ARCH(1) & 0.058912 & 0.019714 & 2.359412 & 0.0274 \\
\hline GARCH(1) & 0.874568 & 0.018541 & 57.60448 & 0.0000 \\
\hline \multicolumn{5}{|c|}{$r_{1}=0.00087+0.04126 \gamma$} \\
$\sigma_{t}^{2}=1.58 \times 10^{-3} 4+0.07781 \varepsilon_{t-1}^{2}+0.05891 \varepsilon_{t-1}^{2} d_{t-1}+0.87456 \sigma_{t-1}^{2}$
\end{tabular}

\section{Conclusions}

GARCH model can be applied to the stock market of our country. Although the model is made and widely used by study the developed country mature financial markets in the process, but it does not prevent applied to the emerging stock market, found after the analysis, the characteristics of the CSI 300 index volatility conditional heteroskedasticity is obvious. It is also proved that the using GARCH model can reflect the rate of return of China stock market volatility changes, and the analysis and research results of high accuracy. From the point of view of time series, the Shanghai and Shenzhen 300 index daily yield fluctuations show a significant variability and volatility clustering. Set of clusters is the related influencing factors of the CSI 300 index, such as information on the stock index fluctuation showing greater volatility tends to then more substantial fluctuations, and smaller fluctuations will then smaller fluctuations. Yields on itself, there is no autocorrelation, but returns the square has such a strong correlation, and is not in general normal distribution, but sequence showing the distribution of the peak and fat tail characteristics, and there are significant GARCH effect and the volatility of the past impact on future gradually decay.

China's securities market volatility clustering characteristics are obvious, there are a lot of irrational factors in the market trading behavior, market price volatility is more intense. The inefficiency of market information makes it difficult to fully display the function of the stock value and the function of resource optimization. Information disclosure system, so that the basic information of the securities market can fully and fully open, give full play to the role of the market, to build a reasonable mechanism for the transmission of information, reduce market speculation atmosphere.

\section{References}

[1] S.Hammoudeh and D.Nguyen, "Dependence of stock and commodity futures markets in China: Implications for portfolio investment”, Emerging Markets Review, vol. 21, (2014), pp. 183-200.

[2] L. Jason and J. Thompson, "Edging effectiveness of stock index futures", European Journal of Operational Research, vol. 163, no. 1, (2005), pp. 177-191.

[3] B. Algieri, "The influence of biofuels, economic and financial factors on daily returns of commodity futures prices", Energy Policy, vol. 69, (2014), pp. 227-247.

[4] A.Antoniou and G. Koutmos, "Index futures and positive feedback trading: evidence from major stock exchanges", Journal of Empirical Finance, vol. 12, no. 2, (2005), pp. 219-238.

[5] I. Francis and S.Kim, "Multiscale hedge ratio between the Australian stock and futures markets: Evidence from wavelet analysis", Journal of Multinational Financial Management, vol. 16, no. 4, (2006), pp. 411-423.

[6] L. Donald, "Availability and settlement of individual stock futures and options expiration-day effects: evidence from high-frequency data", The Quarterly Review of Economics and Finance, vol. 45, no. 4, (2005), pp. 30-747. 
[7] J. Driffill and Z. Rotondi, "Monetary policy and financial stability: What role for the futures market?", Journal of Financial Stability, vol. 2, no. 1, (2006), pp. 95-112.

[8] F. Christos and E. Salvador, "Calendar anomalies in cash and stock index futures: International evidence", Economic Modelling, vol. 37, (2014), pp. 216-223.

[9] R. Yang and L. Xiangyang, "Analysis of linkage effects among industry sectors in China's stock market before and after the financial crisis", Physica A: Statistical Mechanics and its Applications, vol. 41, (2014), pp. 12-20

[10] H. Hongbo and S. Chen, "Financial liberalisation and international market interdependence: Evidence from China's stock market in the post-WTO accession period", Journal of International Financial Markets, Institutions and Money, vol. 33, (2014), pp. 434-444.

[11] L. Hong "The impact of China's stock market reforms on its international stock market linkages", The Quarterly Review of Economics and Finance, vol. 52, no. 4, (2012), pp. 358-368. 
International Journal of Security and Its Applications

Vol. 11, No. 3 (2017) 